\title{
Sosyal Medya Bağımlılı̆̆ı ve İyilik Hali: Romantik İlişkilerde Mükemmeliyetçiliğin Aracılık Rolü
}

\author{
DOI: 10.26466/opus.597950
}

\author{
$*$

\section{Begüm Satıc1 *} \\ * Dr. Öğr. Üyesi, Artvin Çoruh Üniversitesi, Eğitim Fakültesi, Artvin / Türkiye \\ E-Posta: begum@artvin@edu.tr \\ ORCID: 0000-0003-2161-782X
}

Öz

Bu çalışmanın amacı romantik ilişkilerde mükemmeliyetçiliğin sosyal medya bağımlılı̆̆ı ile iyilik hali arasındaki aracılık rolünü incelemektir. Çalışmanın katılımcılarını yaşları 18 ile 31 arasında değişen $($ Ort $=20.80, S S=2.18), 195^{\prime} i$ kadın ve 155'erkek üniversite öğrencisi oluşturmaktadır. Katılımcılar İyilik Hali Ölçeği, Sosyal Medya Bozukluğu Ölçeği ve Romantik İlişkilerde Mükemmeliyetçilik Ölçeğini doldurmuşlardır. Bu çalışmada öne sürülen hipotez modelini test etmek için Yapısal Eşitlik Modellemesi (YEM) ve bootstrapping tekniği kullanılmıştır. YEM ve bootstrapping sonuçları; (a) sosyal medya bağımlılığının romantik ilişkilerde mükemmeliyetçiliği pozitif yordadığını; (b) sosyal medya bağımlılı̆̆ının iyilik halini negatif yordadığını; (c) romantik ilişkilerde mükemmeliyetçiliğin iyilik halini negatif yordadığını; (d) sosyal medya bağımlığı ile iyilik hali arasında romantik ilişkilerde mükemmeliyetçiliğin aracılık ettiğini ortaya koymuştur. Sonuç olarak üniversite öğrencilerinde sosyal medya bağımlılı̆̆ı iyilik halini hem doğrudan hem de dolaylı bir şekilde yordamakta ve romantik ilişkilerde mükemmeliyetçilik de bu iki değişken arasında aracılık rolü yapmaktadır. Elde edilen bulgular ilgili alan yazın ışı̆̆ında tartışılmış ve sinırlıklar sunulmuştur.

Anahtar Kelimeler: Sosyal medya bağımlılı̆̆ı, iyilik hali, romantik ilişkilerde mükemmeliyetçilik, yapısal eşitlik modellemesi, bootstrapping 


\title{
Social Media Addiction and Flourishing: The Mediating Role of Romantic Relationship Perfectionism
}

\begin{abstract}
The aim of current research is to investigate the mediation role of romantic relationship perfectionism on the effect of social media addiction on flourishing in university students. The participants were 199 females and 155 males and ranged in age from 18 to 31 years old $(M=20.80, S D=2.18)$. The participants filled out the Flourishing Scale, the Social Media Disorder Scale, and the Romantic Relationship Perfectionism Scale. The present research utilized the Structural Equation Modelling (SEM) and bootstrapping techniques to examine the hypothesized research model. The SEM and bootstrapping results revealed that (a) social media addiction positively predicted on romantic relationship perfectionism; (b) social media addiction negatively predicted on flourishing; (c) romantic relationship perfectionism negatively predicted on flourishing; (d) social media addiction predicted flourishing via mediation of romantic relationship perfectionism. The findings suggested that social media addiction associated with flourishing both directly and indirectly, romantic relationship perfectionism mediated the association between social media addiction on flourishing in university students. The findings were discussed in the light of the literature and limitations were presented
\end{abstract}

Keywords: Social media addiction, flourishing, romantic relationship perfectionism, structural equation modelling, bootstrapping 


\section{Giriş}

Sosyal medya hayatımıza girene kadar gazete, televizyon ve tek bir internet sitesi bile bilgi edinmek için yeterliyken günümüzde sosyal medya milyonlarca katılımcının anlık olarak bilgileri yaymasına imkân vererek bilgi edinme açısından sınırsız fırsatlar sunmaktadır. Sosyal medyadan elde edilen bilgiler dünyada olup biten genel geçer olayların yanı sıra özel olarak da tek tek etkileşimde bulunulan kişilerin hayatlarında neler olup bittiği ile ilgili fikir sahibi olmada ve hatta fikir beyan etmede bireye birçok olanak sunmaktadır (Joseph, 2019). Facebook, Twitter, Instagram, Foursquare gibi ağlar kullanıcıların kendi hayatlarıyla ya da dünya ile ilgili haberleri anında paylaşma, gittikleri bir mekândan ya da aldıkları yeni bir üründen memnuniyet derecelerini bildirme ve böylelikle diğerlerine bir fikir sağlama açısından da oldukça fazla kullanılır duruma gelmiştir. Sosyal medya insanları birbirine bağlamakla kalmayıp aynı zamanda güncel kalmanın ve eleştiri ya da beğenileri paylaşmanın da bir yolu olmaktadır. Öte yandan bireyler bu sitelerde kişisel profiller oluşturarak hem gerçek hayattaki arkadaşları ile etkileşime girip hem de benzer ilgi alanlarına sahip yeni çevrimiçi arkadaşlıklar edinebilmekte ve kendilerini farklı bir şekilde tanitarak bambaşka bir hayat da sürebilmektedirler (Griffiths, 2013). Dolayısıyla bilgiye erişimi bu kadar kolay kılan ve kullanıcılara neredeyse her istediklerini sunan bir teknoloji gün geçtikçe daha fazla kişiye hitap etmekte ve büyümektedir (Cabral, 2008).

Son araştırmalara göre dünya nüfusunun \%45'i yani yaklaşık 3 milyar 500 milyon insan aktif olarak sosyal medyayı kullanmaktadır. Türkiye'ye bakıldığında ise ülke nüfusunun \%72'sine denk gelen yaklaşık 59 milyon 500 bin kişinin aktif sosyal medya kullanıcısı olduğu görülmektedir (Digital Report, 2019). Bu verilere göre geçen yıldan itibaren ülkemizde sosyal medya kullanan kişi sayısı 3 milyon kişi artmıştır. Sosyal medya kullanımının bu denli artması elbette ki akıllara sürekli çevrimiçi kalan bireylerin gündelik hayatlarına bu durumun nasıl yansıdığı, ilişkilerini ve bireysel ruh sağlıklarını nasıl etkilediği sorusunu getirmektedir. Sosyal medyanın kontrolsüz bir şekilde kullanılması bireyin yaşamındaki diğer sorumluluklarını yerine getirmeyi engellemeye başladığında sosyal medya bağımlılı̆̆ından bahsetmek mümkün hale gelmektedir (Ryan, Chester, Reece ve Xenos, 2014). Aynı zamanda sosyal ağlarda bu denli 
fazla vakit geçiren kişilerin sanal gerçeklikten etkilenerek romantik ilişkilerinde gerçekçi olmayan mükemmel standartları arayacakları ve kişisel iyilik hallerinde bir takım sorunlar yaşamalarına da sebep olacağı düşünülmektedir. Bu çalışma da sosyal medya bağımlılığı ile iyilik hali arasında romantik ilişkilerdeki mükemmeliyetçiliğin rolünü inceleyerek alan yazına teorik ve pratik açıdan katkı sunmayı hedeflemektedir.

\section{Kuramsal Çerçeve}

\section{Sosyal Medya Bağımlılı̆̆ı}

İnternetin bağımlılık derecesinde kullanımı araştırmacılar tarafından çalışlan bir konu olmakla birlikte son zamanlarda sosyal medya kullanımının bir hayli artmasıyla internet bağımlılı̆̆ının da bir alt kategorisi gibi görülen sosyal medya bağımlılığı incelenmeye başlanmıştır (Frangos, 2009). Günümüzde bireyler bir değil birden fazla sosyal ağda aktif kullanıcı olarak yer almakta ve bu mecralarda önemli miktarda zaman harcamaktadırlar (Digital Report, 2019). Dolayısıyla günlük işlevselliklerini kaybedecek derecede zamanlarını sosyal ağlarda geçiren bireyler sorunlu ve bağıml-lık yapıcı bir noktaya gelmişlerdir. Araştırmacılar ruh hali değişikliği (sosyal medya sitelerinde vakit geçirmenin olumsuz bir değişikliğe yol açmas1), belirginlik (sosyal medya ile davranışsal, bilişsel ve duygusal olarak meşgul olma), tolerans (sosyal medya kullanımının gittikçe artması), yoksunluk belirtileri (sosyal medya kullanımı kısıtlandığında ya da durdurulduğunda rahatsız edici fiziksel ve duygusal semptomlar yaşamak), çatışma (sosyal medya kullanımı nedeniyle kişisel ve kişilerarası problemler yaşamak) ve yeniden nüksetme (bir süre bağımlılık nesnesinden uzak kalabildikten sonra aşırı bir şekilde yeniden sosyal medya kullanımına geri dönme) gibi faktörleri içeren davranışsal ve maddeyle ilişkili bağımlılık semptomlarının çoğunu sosyal medya bağımlılığı geliştiren kullanıcıların da sergilediklerini ortaya koymuşlardır (Andreassen, 2015; Ryan vd., 2014).

Bağımlılığa yönelik geliştirilen biyopsikososyal yaklaşımın yanı sıra sosyal medya bağımlılığının sebep olduğu psikososyal faktörlerin anlaşılması da oldukça önemli görülmektedir. Bu açıdan ele alındığında sosyal medya bağımlılığı ile internet oyun bağımlılığı (Andreassen vd., 2016) ve 
internet bağımlılı̆̆ (Monacis, de Polo, Griffiths ve Sinatra, 2017) gibi diğer teknolojik bağımlılık türleri arasında da güçlü ilişkiler olduğu görülmektedir. Ayrıca kişilik özellikleri açısından bakıldığında sosyal medya bağımlılığ1 gösteren kişilerin dürtüsellik (Wu, Cheung, Ku ve Hung, 2013) ve narsisizm (Andreassen, Pallesen ve Griffiths, 2016) gibi sağlıksız kişilik özellikleri de gösterdikleri ortaya konmuştur. Bununla birlikte bağlanma teorisi açısından da güvenli bağlanma stili geliştirilen bireylerin daha büyük sosyal ilişkileri ve bağlantıları bulunurken, Facebook'ta çok fazla zaman geçirip bu sosyal ağlarda kendilerinin başkaları tarafından nasıl algılandıklarını konusunda sürekli endişe duyan kişilerin de endişeli bağlanma stiline sahip bireyler oldukları belirtilmiştir (Lin, 2016). Dolayısıyla sosyal medyaya bağımlılık geliştiren bireylerin ilişkilerinde ne gibi sorunlar yaşayabileceği ve günlük yaşantılarında nasıl sıkıntılarla baş başa olacakları da ortaya konması gereken cevaplar arasında yerini almaktadır.

\section{Romantik İlişkilerde Mükemmeliyetçilik}

Mükemmeliyetçilik bireyin yaşamının her alanında olduğu gibi romantik ilişkilerini de etkileyen bir durumdur (Stoeber ve Stoeber, 2009). Mükemmeliyetçilik ve romantik ilişkiler söz konusu olduğunda Hewitt ve Flett (1996)'in mükemmeliyetçiliğe çok boyutlu bir bakış açısı sunan modelinden türeyen ikili ilişkilerde mükemmeliyetçilik (dyadic perfectionism) kavramından söz etmek gerekmektedir. İkili ilişkilerde mükemmeliyetçilik partner odaklı mükemmeliyetçilik (partner oriented perfectionism) ve partnerden algılanan (partner prescribed perfectionism) mükemmeliyetçilik olarak kategorize edilmektedir (Stoeber, 2012). Romantik İlişkilerde Mükemmeliyetçilik Ölçeği'ni geliştiren Matte ve Lafontaine (2012) ise partnerden algılanan mükemmeliyetçilik için kendine yönelik mükemmeliyetçilik ve partner odaklı mükemmeliyetçilik için ise partnere yönelik mükemmeliyetçilik kavramlarını kullanmaktadır. Partnere yönelik mükemmeliyetçilik, başkalarına yönelik mükemmeliyetçilik kavramına dayanmaktadır ve diğerinden beklenen yüksek ve gerçekleştirilmesi mümkün olmayan standartları ifade etmektedir. Kendine yönelik mükemmeliyetçilik ise sosyal düzene yönelik mükemmeliyetçilik ile benzer bir kavramdır ve birey partneri tarafından konulmuş bir takım standartlar olduğunu düşünerek bu 
gerçekçi olmayan mükemmeliyetçi beklentileri yerine getirmek için çabalamaktadır (Habke, Hewitt ve Flett, 1999; Haring, Hewitt ve Flett, 2003).

Partnere yönelik mükemmeliyetçilikte bireylerin eleştiriye karşı savunmacı yaklaşımları, kendi kusurlarını görmezden gelme, mükemmeliyetçi standartları başkalarına uygulama eğilimleri romantik ilişkiler için kaçınılmaz olarak yıkıcı bir durum olarak nitelendirilebilir (Ellis, 2002). Bununla birlikte narsistik özellikler, otoriter kişilik yapısı ve sömürücü tutum da karşı tarafı suçlama eğilimi ile ilişkili görünmektedir (Hewitt ve Flett, 1991). Öte yandan kendine yönelik mükemmeliyetçilik de bireyin hem kendisi hem de eşi için cinsel doyumu da düşüren bir faktör olarak karşımıza çıkmaktadır (Habke vd., 1999). İlişkide bir taraf partnerinden mükemmeliyetçilik algısı hissediyorsa diğer partnerin de aynı şekilde eşinden mükemmeliyetçilik algısı hissettiği görülmektedir. Dolayısıyla romantik ilişkilerde gösterilen mükemmeliyetçilik ilişkiden elde edilen doyumu ve evlilikteki mutluluk düzeyini düşüren bir faktör olarak karşımıza çıkmaktadır (Haring vd., 2003).

\section{İyilik Hali}

İyilik hali (flourishing) kavramı hedonia ve eudaimonia olmak üzere iki teorik alt yapıdan beslenmektedir. Hedonia, bireysel zevk alma ve acıdan kaçınmayı ifade eden öznel iyi oluş kavramına işaret ederken (Diener, Lucas ve Oishi, 2003) eudemonia, yaşamdaki amaç ve anlamın öznel olarak deneyimlenmesini içeren daha çok bireysel ve toplumsal anlamda bireyin gelişimini içeren psikolojik iyi oluşu ifade etmektedir (Ryff ve Singer, 2008). Bu bağlamda hedonik iyi oluşun daha çok bireyci batı kültürünün, eudomik iyi oluşun ise akrabalık ve dostluk gibi ilişkilerin ön plana çıtığı, topluma katkının önemsendiği doğu kültürlerinin ruhsal yapısını yansıttığı ifade edilmektedir (Duan, Ho, Tang, Li ve Zhing, 2014). Dolay1sıyla hem bireysel ihtiyaçların yerine getirilmesinden hem de toplumsal ilişkilerden haz duymayı içeren iyilik hali kavramı farklı ülkelerde kullanılabilir köklü bir yapı olarak karşımıza çıkmaktadır (Tang, Guo ve Gopinath, 2016). İyilik hali bilişsel, psikolojik, duygusal ve sosyal gelişimin bir göstergesi olmakla birlikte fiziksel sağlığın da bir belirleyicisi olarak kabul 
edilmektedir. Bu bağlamda bu kavramının iyi oluşun birçok yönünü birleştirmesiyle birlikte geniş kapsamlı bir yapı olduğunu da söylemek mümkündür (Hone vd., 2014).

Hümanistik psikoloji teorilerine (Ryff, 1989; Ryan ve Deci, 2000) de dayanan iyilik hali; yeterlilik, ilişki kurma ve kendini kabul ihtiyacı gibi insanın evrensel psikolojik ihtiyaçlarına atıf yapan bir kavramdır (Diener vd., 2010). Yaşamın genel olarak olumlu yönde gittiğini ifade eden iyilik hali, iyi hissetmenin ve işlevsel olmanın bir bileşimi olarak ifade edilmektedir. Aynı zamanda kişinin zihinsel anlamda refah içinde ve sağlıklı olmasını da betimlemektedir (Huppert ve So 2009). Bireyin yaşam amaçları, başkaları ile pozitif ilişkiler, kendi için önemli faaliyetlerde yetkin hissetme ve iyimserlik gibi olumlu işlevsellik göstergelerinin iyilik hali üzerinde yadsınamaz bir etkisi olduğu görülmektedir (Ryan ve Deci, 2002). Bu bağlamda başkalarından destek almanın ötesinde başkalarına yardım etme ve verici olmanın da bireyin kendi iyilik hali için önemli olduğu ortaya konmaktadır (Dunn, Aknin ve Norton, 2008).

\section{Araștırmanın Amacı}

İnternetle ilgili bağımlılıklara yönelik yapılan ilk araştırmalar sanal ortamlarda çok fazla vakit geçirmenin bireylerde sosyal, psikolojik ve mesleki anlamda yıpranmaların meydana geldiğini dile getirmiştir (Young, Pistner, O'Mara ve Buchanan, 1999). Son zamanlarda yapılan araştırmalar da bu bilgileri destekler nitelikte olmakla beraber sosyal medya bağımlılığın depresyon ve kaygı düzeylerini arttırdığına yönelik bulgular ortaya konmaktadır (Lenhart, Purcell, Smith ve Zickuhr, 2010; Seabrook, Kern ve Rickard, 2016). Özellikle Facebook kullanımı üzerine yapılan araştırmalar Facebook'un aşırı kullanımının depresyonla ilişkili olduğunu ortaya koymaktadır (Pantic vd., 2012; Jelenchick, Eickhoff ve Moreno, 2013). Anksiyete bozuklukları, duygudurum bozuklukları, madde kullanımı gibi diğer ruhsal bozukluklar ve düşük duygusal iyi oluş ile de aşırı internet kullanımının ilişkisi olduğu görülmektedir (Arısoy, 2009; Rücker, Akre, Berchtold ve Suris, 2015). Sosyal medyanın aşırı kullanımının da benzer şekilde ruhsal sorunlara neden olduğu ortaya konmuştur (Pantic, 2014). Bireyin ruh sağlığıyla iç içe olan iyilik halinin de sosyal medya bağımlılığından olumsuz bir şekilde etkileneceği ön görülebilir. 
$\mathrm{Bu}$ araştırmanın diğer bir değişkeni olan romantik ilişkilerde mükemmeliyetçilik kavramı ve sosyal medya bağımlılığı ile ilgili birebir yapılan çalışmalara rastlanmasa da genellenmiş problemli internet kullanımının kendine yönelik mükemmeliyetçilik teriminin temelini oluşturan sosyal düzene yönelik mükemmeliyetçiliğe (Haring vd., 2003) yönelik bir risk faktörü olduğu belirtilmektedir (Casale, Fioravanti, Flett ve Hewitt, 2015). Bir başka çalışmada ise gerçekçi olmayan ilişki beklentilerinin de içinde bulunduğu bilişsel çarpıtmalar ile problemli internet kullanımı arasında pozitif yönde anlamlı ilişkiler bulunmuştur (Çelik ve Odacı, 2013). Bu doğrultuda internet bağımlılığının alt kategorisi olarak görülen sosyal medya bağımlılığ 1 ile temelinde bilişsel çarpitmaların da yer aldığı romantik ilişkilerde mükemmeliyetçilik kavramının ilişkili olabileceği düşünülmektedir.

Son olarak romantik ilişkilerde mükemmeliyetçilik ve iyilik hali ile ilgili yapılan araştırmalar incelendiğinde ilişkide partnere yönelik mükemmeliyetçiliğin fazla olduğu durumlarda ilişkide sürekli bir sıkıntı hali ve uyumsuzluk olduğunu ortaya konmaktadırlar (Flett, Hewitt, Shapiro ve Rayman, 2001). Kendine yönelik mükemmeliyetçilik söz konusu olduğunda ise çatışmaya götürücü tepkilerde bulunma, partnere karşı duyarsızlık ya da saplantılı bir şekilde onun eksikliklerini arama ve daha düşük düzeyde partner uyumu görülmektedir (Flett vd., 2001). Oysa sosyal ilişkilerde diğeri tarafından saygı görmek iyilik halini önemli ölçüde etkileyen temel bir ihtiyaçtır (Ryff, 1989). Yapılan bir araştırmaya göre partnerlerin birbirine destek olduğu, birlikte kaliteli vakit geçirdikleri ve sağlıklı iletişim kalıpları sergiledikleri bir ilişkide partnerlerin ikisinin de iyilik hallerinin olumlu yönde etkilendiği ortaya konmuştur (Blanchard, Hawkins, Baldwin ve Fawcett, 2009). Çünkü çiftlerin birbirlerine karşı tutarlı olmaları ve birbirlerine olumlu özelliklerini ifade etmeleri ilişkilerinde ortak hedeflere ulaşmalarını sağlayarak iyilik hallerine katkıda bulunmaktadır (Fowers ve Owenz, 2010). Dolayısıyla romantik ilişkilerde mükemmeliyetçi tutumun ilişkinin yanı sıra kişinin kendisine ve karşısındakine duygusal açıdan yatırım yapması ve gelişmesine yardımcı olan iyilik halini de olumsuz etkileyebileceği dile getirilebilmektedir.

Sonuç olarak sosyal medyanın kullanımının gittikçe yaygınlaşarak bireyler için birinci öncelik haline gelmesi, romantik ilişkileri olumsuz etkilemekle birlikte fiziksel ve ruhsal olarak insanların kendi sağlıkları için de 
bir risk unsuru olduğu görülmektedir. Sanal dünyadaki yaşantıların kusursuzluğu akıllarda soru işareti bıraksa da sosyal ağları sık kullanan bireyler için bir süre sonra bu durum yeni bir gerçeklik algısı yaratmakta ve yaşamlarında bu gerçekçi olmayan mükemmeli aramalarına sebep olabilmektedir. Dolayısıyla bireylerin romantik ilişkilerine de etki edebilecek bu mükemmeliyetçiliğin iyilik hallerini nasıl etkileyeceği araştırılmaya değer görülmektedir. Bu çalışmada ele alınan değişkenlerin ayrı ayrı incelendiği çalışmalar mevcut olsa da değişkenlerin birlikte ele alındığ araştırmalara rastlanmamış olması açısından da bu araştırma önemli görülmektedir. Bu yüzden bu araştırmanın amacı sosyal medya bağımlılığ ile iyilik hali arasında romantik ilişkilerde mükemmeliyetçiliğin aracılık rolünün incelenmesidir. Bu amaç doğrultusunda Şekil 1'de yer alan hipotezler oluşturulmuştur.

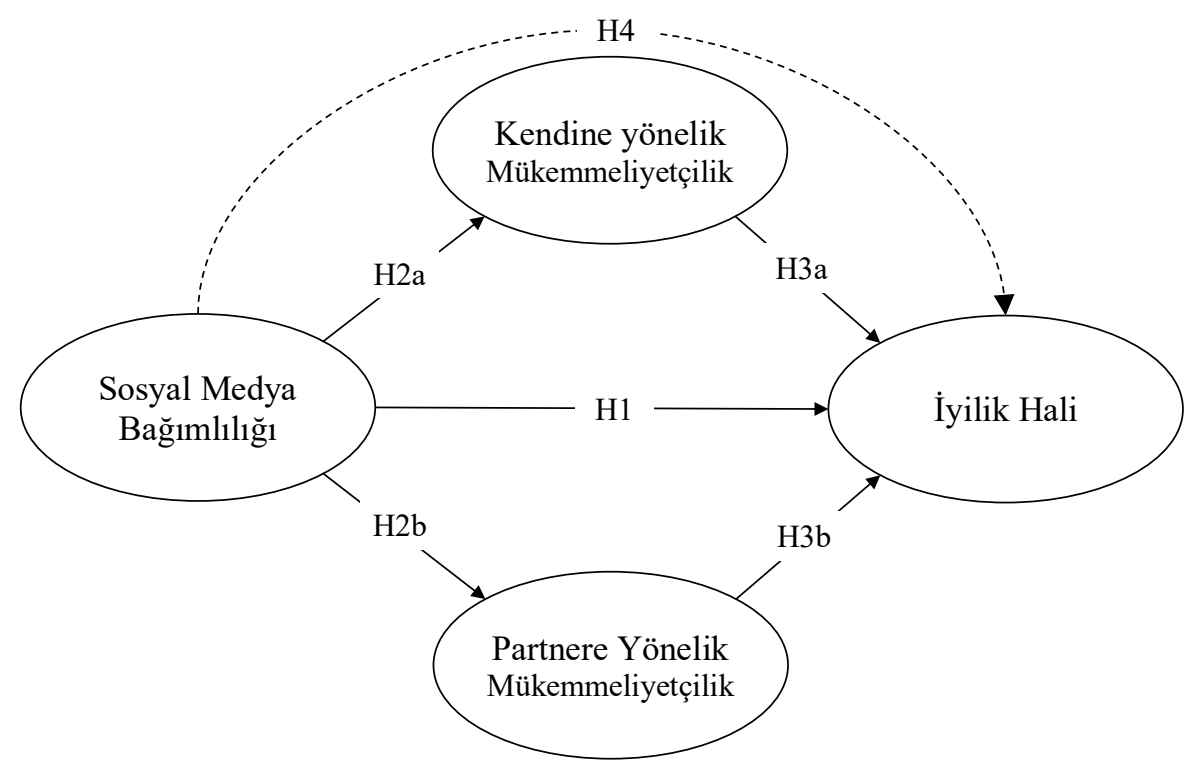

Şekil 1. Hipotez modeli

- H1. Sosyal medya bağımlılığı iyilik halini negatif yordar.

- H2a. Sosyal medya bağımlılığı kendine yönelik mükemmeliyetçiliği pozitif yordar. 
- H2b. Sosyal medya bağımlılığı partnere yönelik mükemmeliyetçiliği pozitif yordar.

- H3a. Kendine yönelik mükemmeliyetçilik iyilik halini negatif yordar.

- H3b. Partnere yönelik mükemmeliyetçilik iyilik halini negatif yordar.

- H4. Sosyal medya bağımlılığı kendine ve partnere yönelik mükemmeliyetçilik aracılığıyla iyilik halini yordar.

\section{Yöntem}

\section{Katılımcilar}

Bu araştırmanın katılımcılarını Artvin Çoruh Üniversitesi Eğitim ve FenEdebiyat Fakültelerinde öğrenim gören 354 üniversite öğrencisi oluşturmaktadır. Katılımcıların yaşları 18 ile 31 arasında değişmekte olup; yaş ortalamaları 20.80, standart sapması 2.18'dir. Yüz doksan dokuzu (\%56.2) kadın ve 155'i (\%43.8) erkek olan katılımciların; 96' s1 (\%27) birinci sınıfta, 91'i (\%26) ikinci sınıfta, 99'u (\%28) üçüncü sınıfta ve 68'i (\%19) dördüncü sinıfta öğrenim görmektedirler.

\section{Veri Toplama Araçlan}

İyilik hali: Katılımcıların iyilik hali düzeylerini ölçebilmek amacıyla Diener ve meslektaşları (2010) tarafından geliştirilen ve Türkçeye Telef (2013) tarafından uyarlanan İyilik Hali Ölçeği (Flourishing Scale) kullanılmıştır. Ölçek 8 maddeden (örn. Başkalarının mutlu ve iyi olmasına aktif olarak katkıda bulunurum.) ve 7'li Likert-tipi derecelemeden (1: Kesinlikle katılmiyorum, 7: Kesinlikle katılıyorum) meydana gelmektedir. Ölçekten elde edilebilecek olası puanlar 8 ile 56 arasında değişmekte ve yükselen puanlar iyilik halinin de yükseldiğine işaret etmektedir. Ölçeğin Türkçeye uyarlama çalışmasında tek boyutlu yapının iyi uyum verdiği (GFI = .96, $\mathrm{NFI}=.94, \mathrm{RFI}=.92, \mathrm{CFI}=.95, \mathrm{IFI}=.95, \mathrm{SRMR}=.04)$ ve güvenirliğinin de kabul edilebilir düzeyde olduğu belirtilmiştir ( $\alpha=.80$; Telef, 2013). Ölçeğin güvenirlik katsayısının bu çalışma kapsamında da yeterli düzeyde olduğu saptanmıştır $(\alpha=.82)$. 
Sosyal medya bağımlılı̆̆ı: Katılımcıların sosyal medya bağımlılıklarını ölçebilmek amaciyla van den Eijnden Lemmens ve Valkenburg (2016) tarafından geliştirilen ve Türkçeye Savcı, Ercengiz ve Aysan (2018) tarafından uyarlanan Sosyal Medya Bozukluğu Ölçeği (Social Media Disorder Scale) kullanılmıştır. Ölçek 9 maddeden (örn. Sosyal medyayı kullanacağın anı düşünmekten başka bir şey düşünmediğin oldu mu?) ve 5'li Likert-tipi derecelemeden (0: Hiçbir zaman, 4: Her zaman) meydana gelmektedir. Ölçekten elde edilebilecek olası puanlar 0 ile 36 arasında değişmekte ve yükselen puanlar sosyal medya bağımlılığının da yükseldiğine işaret etmektedir. Ölçeğin Türkçeye uyarlama çalışmasında tek boyutlu yapının iyi uyum verdiği $(\mathrm{GFI}=.95, \mathrm{TLI}=.96, \mathrm{AGFI}=.91, \mathrm{CFI}=.97, \mathrm{IFI}=.97$, RMSEA $=.055)$ ve güvenirliğinin de kabul edilebilir düzeyde olduğu belirtilmiştir ( $\alpha=$.86; Savcı vd., 2018). Ölçeğin güvenirlik katsayısının bu çalışma kapsamında da yeterli düzeyde olduğu saptanmıştır $(\alpha=.81)$.

Romantik ilişkilerde mükemmeliyetçilik: Katılımcıların romantik ilişkilerde mükemmeliyetçilik düzeylerini ölçebilmek amaciyla Matte ve LaFontaine (2012) tarafından geliştirilen ve Türkçeye Özteke, Büyükbayraktar ve Kesici (2015) tarafından uyarlanan Romantik İlişkilerde Mükemmeliyetçilik Ölçeği (Romantic Relationship Perfectionism Scale) kullanılmıştır. Ölçek 14 maddeden (örn. Sevgilimle sohbet ederken bütün gerçekleri söylemek benim için önemlidir) ve 7'li Likert-tipi derecelemeden (1: Hiçbir şekilde katılmıyorum, 7: Tamamen katılıyorum) meydana gelmektedir. Ölçek kendine yönelik mükemmeliyetçilik ve partnere yönelik mükemmeliyetçilik olmak üzere iki boyuttan oluşmaktadır. Ölçeğin Türkçeye uyarlama çalışmasında iki boyutlu yapının iyi uyum verdiği $(\mathrm{RMR}=.04, \mathrm{RMSEA}=.05 \mathrm{CFI}=.90, \mathrm{GFI}=.95$, AGFI $=.92)$ ve güvenirliğinin de kabul edilebilir düzeyde olduğu belirtilmiştir ( $\alpha=.76$; Özteke vd., 2015). Ölçeğin güvenirlik katsayısının bu çalışma kapsamında da yeterli düzeyde olduğu saptanmıştır (sırasıyla $\alpha=.72$ ve .70 ).

\section{İşlem}

Veriler araştırmacı tarafından bizzat sınıf ortamında yüz yüze olarak elde edilmiştir. Çalışmanın katılımcılarından gönüllü katılım sağlandığına yö- 
nelik bilgilendirilmiş onam alınmıştır. Veri toplama setinde sırasal yanl1lığ1 (sürekli aynı ölçeğin aynı yerde kalması) bertaraf edebilmek karşıt dengeleme (counter-balancing) uygulanmıştır. Karşıt dengeleme için ölçeklerin sıralarının değiştiği üç ayrı veri toplama seti oluşturulmuştur.

\section{Verilerin Analizi}

Araştırmada ilk olarak değişkenlere ait betimleyici istatistikler incelenmiş ve değişkenler arası ilişkiler ele alınmıştır. Ardından Anderson ve Gerbing' in (1988) önerisi doğrultusunda iki aşamalı Yapısal Eşitlik Modellemesi kullanılmıştır. Bu öneride öncelikle ölçüm modeli (measurement model) test edilmektedir. Ölçüm modelinin doğrulanmasının ardından hipotetik olarak oluşturulan yapisal model (structural model) incelenmektedir. Yapısal modelde en iyi modeli saptayabilmek için tam ve kısmı aracı modeller ile alternatif modeller sinanmakta ve karar aşamasında AIC ve ECVI değerlerine bakılmaktadır. Bu aşamada AIC ve ECVI değeri küçük olan modelin en iyi model olduğu anlaşılmaktadır (Akaike 1987; Browne ve Cudeck 1993).

Çalışmada kullanılan değişkenler tek boyutlu oldukları için YEM'de parselleme yapılarak sanal iki faktör oluşturulmuştur. Parselleme; ölçümün güvenirliğinin artırılması ve normalliğin güçlendirilmesi açısından önerilen bir teknik olarak görülmektedir (Nasser-Abu Alhija ve Wisenbaker, 2006).

Bu çalışmada YEM'de elde edilen en iyi modelin yollarının anlamlılığına ek kanıt sağlamak amaciyla bootstrapping tekniği de kullanılmıştır. 10,000 bootstrapping yapılarak katsayı ve güven aralıkları oluşturulmuştur. Güven aralıkları sıfırı kapsamadığı takdirde incelenen yolun anlamlı olduğuna karar verilmektedir (Hayes, 2018).

Çalışmadaki analizler IBM SPSS ${ }^{\circledR}$ Statistics 21.00 ve AMOS Graphics aracılığıyla yapılmıştır. 


\section{Bulgular}

\section{Ön Analizler}

Değişkenlere ait betimleyici istatistikler olarak ortalama, standart sapmak, çarpıklık ve basıklık katsayıları ile değişkenler arasındaki ilişkileri Tablo 1 'de yer almaktadır.

Tablo 1. Betimleyici İstatistikler ve Korelasyon

\begin{tabular}{|c|c|c|c|c|c|c|c|}
\hline \multirow[b]{2}{*}{ Değişken } & \multicolumn{4}{|c|}{ Betimleyici İstatistik } & \multicolumn{3}{|c|}{ Korelasyon } \\
\hline & Ort & SS & Ç & $B$ & 1 & 2 & 3 \\
\hline 1. İyilik hali & 41.32 & 7.56 & -.99 & 1.43 & - & & \\
\hline 2. Sosyal medya bağımlılığı & 19.11 & 6.46 & .57 & -.32 & $-.35^{* *}$ & - & \\
\hline 3. KY mükemmeliyetçilik & 30.49 & 7.10 & .01 & -.49 & $-.27^{* *}$ & $.28^{* *}$ & - \\
\hline 4. PY mükemmeliyetçilik & 27.72 & 5.95 & .17 & .03 & $-.30^{* *}$ & $.31^{* *}$ & $.38^{* *}$ \\
\hline
\end{tabular}

Tablo 1'de yer aldığı üzere iyilik hali ile sosyal medya bağımlılığı $r_{(354)}$ $=-.35$, \%95G.A. [-.44, -.26], kendine yönelik mükemmeliyetçilik $r_{(354)}=-.27$, \%95G.A. [-.36, -.17] ve partnere yönelik mükemmeliyetçilik $r_{(354)}=-.30$, \%95G.A. [-.42, -.20] negatif yönde anlamlı ilişkiler göstermektedir. Diğer taraftan sosyal medya bağımlılığının kendine yönelik mükemmeliyetçilik $r(354)=.28, \% 95$ G.A. $[.18, .37]$ ve partnere yönelik mükemmeliyetçilik $r_{(354)}$ $=.31$ \% \% 95G.A. [.21, .40] arasında ise pozitif yönde anlamlı ilişkiler saptanmiştır.

\section{Yapısal Eşitlik Modellemesi}

Ölçüm modeli:Yapısal eşitlik modellemesinin ilk aşaması olan ölçüm modelinde dört adet gizil değişken (iyilik hali, sosyal medya bağımlılığı, kendine yönelik mükemmeliyetçilik ve partnere yönelik mükemmeliyetçilik) ile bu gizil değişkenleri oluşturan 8 adet gözlenen değişkene yer verilmiştir. Gerçekleştirilen analiz sonucunda ölçüm modelinin iyi uyum verdiği görülmüştür; $\left[\chi^{2}(14,354)=21.93, \chi^{2} / \mathrm{sd}=1.56, p<.001\right.$; CFI = .99; GFI = .98; $\mathrm{AGFI}=.96 ; \mathrm{NFI}=.97 ; \mathrm{SRMR}=.024 ; \mathrm{RMSEA}=.040]$. Bununla birlikte ölçüm modelindeki yol katsayılarının .66 ile .98 arasında değiştiği ve tüm yol katsayılarının anlamlı olduğu belirlenmiştir. Dolayısıyla ölçüm modelinin 
yapısal modellerin test edilmesi için yeterli değerlere sahip olduğu anlaşılmıştır.

Yapısal model:Yapısal modelde öncelikle sosyal medya bağımlılığı (bağımsız değişken) ile iyilik hali (bağımlı değişken) ilişkisinde romantik ilişkide mükemmeliyetçiliğin tam aracılığ $ı$ test edilmiştir. Tam aracı modelde bağımsız değişkenden bağımlı değişkene giden doğrudan yol bulunmamaktadır. Analiz sonucunda tam aracı modelde SRMR (.09) ve RMSEA (.10) katsayılarının kabul edilebilir sınırlar içerisinde olmadığı görülmüştür. Ardından kısmı aracı modelin test edilmesine geçilmiştir. Kısmı aracı modelde bağımsız değişkenden bağımlı değişkene giden doğrudan yol eklenmektedir. Kısmı aracı modelin uyum iyiliği indeksleri göz önüne alındığında tümünün kabul edilebilir sınırlar içerisinde olduğu belirlenmiştir $\left[\chi^{2}(15,354)=57.45, \chi^{2} / \mathrm{sd}=3.83, p<.001 ; \mathrm{CFI}=.96 ; \mathrm{GFI}=.96\right.$; AGFI $=$ .91 ; NFI $=.95 ;$ SRMR $=.07$; RMSEA $=.08$ ]. Ayrıca bu modelde tüm yol katsayılarının da anlamlı olduğu saptanmıştır.

Diğer taraftan çalışmanın doğası gereği olası en iyi modeli belirleyebilmek için hipotez edilen modelden farklı olarak kurulan alternatif modeller sınanmıştır. Birinci alternatif modelde bağımsız değişken olarak romantik ilişkilerde mükemmeliyetçilik; bağımlı değişken olarak iyilik hali; aracı değişken olarak sosyal medya bağımlılı̆̆ı olacak şekilde yapısal model kurulmuştur. Birinci alternatif modeline ait uyum iyiliği indekslerinin çoğunun kabul edilebilir sınırlar içinde olmadığ 1 anlaşılmıştır $\left[\chi^{2}(17,354)=\right.$ 96.23, $\chi^{2} / \mathrm{sd}=5.66, p<.001 ; \mathrm{CFI}=.92 ; \mathrm{GFI}=.94 ; \mathrm{AGFI}=.87 ; \mathrm{NFI}=.91$; $\mathrm{SRMR}=.13$; RMSEA = .12]. İkinci alternatif modelde bağımsız değişken olarak romantik ilişkilerde mükemmeliyetçilik; bağımlı değişken olarak sosyal medya bağımlılığı; aracı değişken olarak iyilik hali olacak şekilde yapisal model kurulmuştur. Bu modelde de uyum iyiliği indekslerinin kabul edilebilir olmadığı anlaşılmıştır; $\left[\chi^{2}(17,354)=105.61, \chi^{2} / \mathrm{sd}=6.21, p<.001\right.$; $\mathrm{CFI}=.91 ; \mathrm{GFI}=.93 ; \mathrm{AGFI}=.85 ; \mathrm{NFI}=.89 ; \mathrm{SRMR}=.13 ; \mathrm{RMSEA}=.12]$. Sınanan tüm modellere ait uyum-iyiliği indeksleri Tablo 2 'de sunulmuştur.

Tablo 2'de görüleceği üzere; çalışmada hipotetik olarak oluşturulan kısmi aracı modelin en iyi uyum iyiliği indekslerine sahip olduğu ifade edilebilir. 
Tablo 2. İncelenen Modellere Ait Uyum-İyiliği İndeksleri

\begin{tabular}{lllll}
\hline Uyum-iyiliği indeksi & Tam Arac1 & Kismı Araci & Alternatif I & Alternatif II \\
\hline$\chi^{2}$ & 72.97 & 57.45 & 96.23 & 105.61 \\
sd & 16 & 15 & 17 & 17 \\
CFI & .94 & .96 & .92 & .91 \\
GFI & .95 & .96 & .94 & .93 \\
AGFI & .89 & .91 & .87 & .85 \\
NFI & .93 & .95 & .91 & .89 \\
SRMR & .09 & .07 & .13 & .13 \\
RMSEA & .10 & .08 & .12 & .12 \\
AIC & 112.97 & 99.45 & 134.23 & 140.61 \\
ECVI & .32 & .28 & .38 & .41 \\
\hline
\end{tabular}

Bununla birlikte tüm modellerin AIC ve ECVI değerleri karşılaştırıld1ğında da yine kısmi aracı modelin en düşük AIC ve ECVI değerlerine sahip olması bakımından da tercih edilecek model olduğu söylenebilir. Dolayısıyla sosyal medya bağımlılığı ile iyilik hali ilişkisinde romantik ilişkide mükemmeliyetçiliğin kısmi aracılık ettiği belirtilebilir. Karar kılınan kısmi aracılık modeline ait standardize edilmiş yol katsayıları Şekil 2'de sunulmuştur.

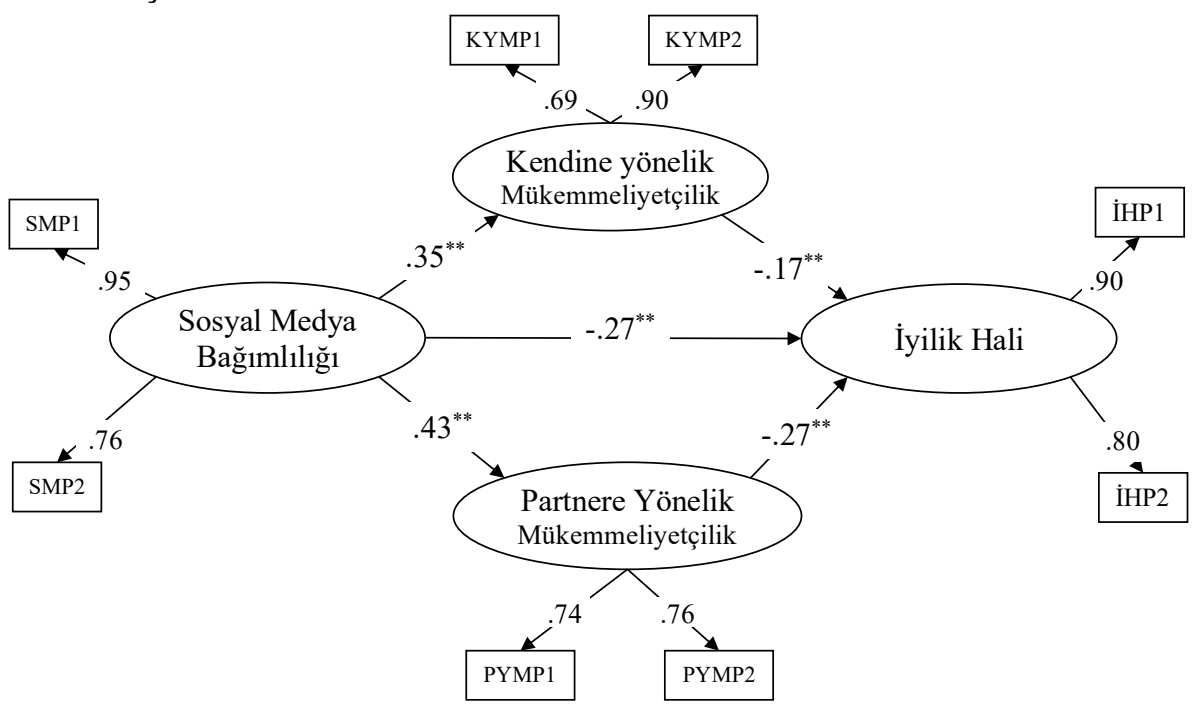

Şekil 2. Kısmı aracı modele ait standardize edilmiş katsayılar

$\mathrm{N}=326 ;{ }^{* *} \mathrm{p}<.01 ; \mathrm{SMP}$ sosyal medya bağımlılığı parselleri; KYMP kendine yönelik mükemmeliyetçilik parselleri; PYMP partnere yönelik mükemmeliyetçilik parselleri; IHP iyilik hali parselleri 


\section{Bootstrapping Tekniği}

Çalışmada hipotetik olarak sınanan ve YEM sonucunda da en iyi model olarak tercih edilen kısmi aracı modele bootstrapping tekniği uygulanmıştır. Modeldeki doğrudan ve dolaylı yolların anlamlılı̆̆ına ek kanıt sağlamak için gerçekleştirilen bootstrapping sonuçları Tablo 3' de sunulmuştur. Bununla birlikte hipotezlere ait sonuçlar da yer almaktadır.

Tablo 3. Standardize Edilmemiş Bootstrapping Değerleri ve Hipotez Sonuçlarn

\begin{tabular}{|c|c|c|c|c|c|c|}
\hline \multirow[b]{2}{*}{ Hipotez } & \multirow[b]{2}{*}{ Yol } & \multirow[b]{2}{*}{ Katsayı } & \multirow[b]{2}{*}{$\mathrm{SH}$} & \multicolumn{2}{|l|}{$\% 95 G A$} & \multirow[b]{2}{*}{ Sonuç } \\
\hline & & & & Alt sinir & Üst sınır & \\
\hline H1 & $\mathrm{SM} \rightarrow \dot{\mathrm{I}} \mathrm{H}$ & -.29 & .09 & -.49 & -.13 & Kabul \\
\hline $\mathrm{H} 2 \mathrm{a}$ & $\mathrm{SM} \rightarrow \mathrm{KYM}$ & .23 & .06 & .12 & .36 & Kabul \\
\hline $\mathrm{H} 2 \mathrm{~b}$ & $\mathrm{SM} \rightarrow \mathrm{PYM}$ & .27 & .05 & .18 & .37 & Kabul \\
\hline $\mathrm{H} 3 \mathrm{a}$ & $\mathrm{KYM} \rightarrow \mathrm{I} H$ & -.27 & .10 & -.49 & -.07 & Kabul \\
\hline $\mathrm{H} 3 \mathrm{~b}$ & $\mathrm{PYM} \rightarrow \mathrm{I} \mathrm{H}$ & -.35 & .16 & -.70 & -.04 & Kabul \\
\hline $\mathrm{H} 4$ & $\mathrm{SM} \rightarrow \mathrm{KYM} / \mathrm{PYM} \rightarrow \dot{\mathrm{I} H}$ & -.16 & .05 & -.28 & -.07 & $\begin{array}{l}\text { Kismi } \\
\text { arac1 }\end{array}$ \\
\hline
\end{tabular}

$S M$ sosyal medya bağımlığı; $\dot{I} H$ iyilik hali; $K Y M$ kendine yönelik mükemmeliyetçilik; $P Y M$ partnere yönelik mükemmeliyetçilik

Tablo 3'de yer alan bootstrapping katsayıları göz önüne alındığında; doğrudan yolların tamamının anlamlı olduğu söylenebilir. Bununla birlikte sosyal medya bağımlılığının kendine ve partnere yönelik mükemmeliyetçiliğin aracılığıyla iyilik halini dolaylı etkilemesinin de anlamlı olduğu belirtilebilir (bootstrap katsayıs1 = -.16, \%95GA = -.28, -.07 ).

\section{Tartışma}

Bu çalışmada sosyal medya bağımlılığı ve iyilik hali arasında romantik ilişkilerde mükemmeliyetçiliğin aracılık rolü incelenmiştir. Bu doğrultuda alan yazındaki araştırmalardan yola çıkarak dört adet hipotez öne sürülmüştür. Çalışmanın bulgularına göre bu dört hipotezin de doğrulandığ 1 görülmektedir.

Araştırmanın birinci hipotezinde sosyal medya bağımlılı̆̆ının iyilik halini negatif yönde yordayacağı öngörülmüştür. Bulgular bu hipotezi de destekler niteliktedir. Alan yazına bakıldığında sosyal medya bağımlılığının çatı kavramı olan problemli internet kullanımının yaşam doyumu 
ve özsaygının düşmesi aracılığıyla psikolojik iyi oluşu da olumsuz etkilediği görülmektedir (Şenol-Durak ve Durak, 2011). Bunun sebebi olarak örneğin Facebook gibi bir sosyal medya platformunda bireylerin kendilerini diğerleri ile kıyaslayıp yapılan paylaşımlardaki kusursuz hayatın kendilerinde olmadığını düşünüp mutsuz olmaları gösterilebilmektedir (Steers, Wickham ve Acitelli, 2014). Sosyal medya aşırı bir şekilde kullanıldığı zaman bireyin arkadaş çevresinin tatil ve alışveriş fotoğraflarına maruz kalması da bireyin yetersizlik duygularını tetikleyerek depresyona sürükleyebilmektedir (Balcı ve Baloğlu, 2018). Öte yandan sosyal medyada kendisini olduğundan farklı bir kişi gibi gösteren bireylerin de iyilik hali ile ilişkili olan yaşam doyumlarının da daha düşük olduğu ortaya konmuştur (Balcı, Gölcü ve Gölcü, 2019). Bu açıdan ele alındığında araştırmanın bu bulgusunun alan yazındaki bilgilerle benzer doğrultuda olduğu görülmektedir.

Araştırmanın ikinci hipotezinde sosyal medya bağımlılığının romantik ilişkilerde mükemmeliyetçiliği pozitif yönde yordayacağı ön görülmüştür. Gerçek yaşamda kendisini yalnız ve mutsuz hisseden bireyler sosyal medyada her şey yolunda ve çok mutluymuş gibi görünerek aslında gösteriş yapmak amacıyla sosyal maskeler takmaktadırlar (Yıldız, 2017). Bu ortamlarda kişiler ilişkilerinin mutsuz anlarındansa hediye aldıkları, lüks bir restorana gittikleri, ya da tatilde çok eğlendikleri anlarını paylaşmaktadırlar. Böylece sanki herkes her zaman mutlu ve kusursuz hayatlar yaşıyor gibi görünmektedir. Sosyal medyada çok fazla vakit geçirip yansıtılan bu sanal gerçeklik algısından etkilenen bireylerin de romantik ilişkilerinde benzer kusursuz hayatı yaşamayı arzulayarak partnerlerinden sürekli beklenti içerisine girmeleri ve partnerlerine yönelik mükemmeliyetçi tutumlar sergiledikleri düşünülebilir. Bununla birlikte sosyal medyayı bağımlılık derecesinde kullanan kişiler neredeyse yaşamlarındaki her ayrıntıyı allayıp pullayıp sosyal medya hesaplarından paylaşarak hem beğenilme ihtiyaçlarını gidermekte hem de artan takipçi sayıları ile kendilerini özel ve önemli hissetmektedirler (Karaca ve Mutlu, 2019). Dolayısıyla her an beğenilme ihtiyacı tatmin olan bu kişilerin gerçek yaşamlarında ve romantik ilişkilerinde de artan beklentileri ile partnerlerine yönelik de mükemmeliyetçi tutumlar sergiledikleri söylenebilir. Öte yandan sosyal medya bağımlılı̆̆ geliştiren bireylerin bu ortamlarda yansıtılan kusursuz güzellik, kusursuz annelik, kusursuz eş imajlarına kapılıp partnerlerinin 
de kendilerinden bu şekilde gerçekdışı beklentiler içinde olduklarını düşünerek kendine yönelik mükemmeliyetçilik tutumları ortaya koydukları düşünülebilir. Sosyal medya bağımlılığı ile ortaya çıkan bu mantıkdışı inançların romantik ilişkilerde de mükemmeliyetçi tutumu geliştirebileceği sonucu alan yazındaki araştırma sonuçları ile de tutarlı görülmektedir.

Araştırmanın üçüncü hipotezinde romantik ilişkilerde mükemmeliyetçiliğin iyilik halini negatif yönde yordayacağı ön görülmüştür. Araştırma bulgularına göre belirtilen bu hipotezin de doğrulandığı görülmektedir. Partnere yönelik mükemmeliyetçilik sergileyen bireylerin düşük düzeyde evlilik uyumu ve zayıf aile ilişkileri içinde oldukları görülmektedir; çünkü bu kişiler ilişkilerindeki sorunları çözerken bile daha az destekleyici tutum içerisinde olmaktadırlar (Hewitt, Flett ve Mikail, 1995). Bireyin hem kendisi hem de partneri için gerçekçi olmayan beklentileri ilişki sorunlarını ve uyumsuzluğu da beraberinde getirmektedir (Haferkamp, 1994). Kendine yönelik mükemmeliyetçilik ve partnere yönelik mükemmeliyetçilik düzeyleri yüksek olan bireyler aile içinde de daha fazla zorluk yaşamaktadırlar (Hewitt, Flett ve Mikail, 1995). Mükemmeliyetçi kaygıların hem klinik hem de klinik olmayan düzeyde psikolojik rahatsızlıklara sebep olduğunu gösteren birçok çalışama mevcuttur (Bardone-Cone vd., 2007; Flett ve Hewitt, 2002; Frost ve DiBartolo, 2002). Bu doğrultuda genel olarak mükemmeliyetçi kaygı gösteren bireylerin hem yaşam doyumlarının azalacağ1 (Mackinnon, Kehayes, Leonard, Fraser ve Stewart, 2017) hem de iyilik hali için risk unsuru olacağı söylenmektedir (Sirois ve Molnar, 2015). Dolayısıyla araştırmanın bu bulgusu da alan yazındaki çalışmalarla desteklenmektedir.

$\mathrm{Bu}$ araştırmanın bulgularıla desteklenen son hipotezi de sosyal medya bağımlılığı ile iyilik hali arasında romantik ilişkilerde mükemmeliyetçiliğin aracılık rolü olduğuna ilişkindir. Bu sonuç birkaç farklı açıdan ele alınabilir. Öncelikle bireyin yaşamdan doyum elde ederek güçlü bir iyilik haline sahip olması için kendisini diğerleri ile karşılaştırdığında benzer standartlara sahip olduğunu görmesi önemlidir (Michalos, 1985). Oysa sosyal medyada yansıtılan kusursuz ve ulaşılması güç kriterlere sahip olamadığını gören ve romantik ilişkilerinde de mükemmeliyetçiliği sağlamak isteyen birey bir tutarsızlık yaşamakta ve iyilik hali bu durum- 
dan olumsuz etkilenmektedir (Bergman, Nyland ve Burns, 2007). Bu durum başka bir açıdan ele alındığında ise sosyal medya amacı daha fazla beğeni almak olan kişiler için hiç gitmeseler de partnerleriyle sanki sürekli tatildeymiş, ya da partneri her gün kendisine hediye alıyormuş gibi gerçek olmayan bir algı oluşturmalarına fırsat sunan bir ortamdır. Dolayısıyla sosyal medya bağımlısı bir kişi için de bu paylaşımlar fazlasıyla özendirici olabilir ve gerçekmiş gibi algılanabilir. Bu doğrultuda bireyler kendi partnerlerine yönelik benzer şekilde ya da belki de daha fazla beklenti içerisine girebilirler. Anı yaşamaktansa onlar da her gelişmeyi sosyal medya hesaplarına koyarak oradaki beğenilerden elde edecekleri hazzı gerçek romantik ilişkilerinden alacakları hazza tercih edebilirler. Dolayısıyla bu durum hem ilişkinin yıpranmasına hem de kişinin iyilik halinin olumsuz bir şekilde etkilenmesine neden olabilir. Sosyal ağlarda çok fazla zaman geçiren bireyin partnerinden beklentiyi arttırması kıskançlığ tetikleyerek iki tarafın da memnuniyetsizliği ile sonuçlanabilir ki ilişkilerinden doyum elde edemeyen bireylerin de iyilik hallerinin olumsuz etkileneceği ön görülebilir. Son olarak bireylerin kendilerini ideal güzellik algısına yaklaştırabilecek şekilde zayıf ya da estetik bir şekilde göstermelerine imkân veren fotoğraf değiştirme uygulamaları sosyal medyada da oldukça fazla kullanılmaktadır. Bu kusursuz paylaşımlara kanan bireyler kendileri de bu şekilde mükemmel görünme telaşına girebilir. Ancak ulaşılamaz bu mükemmeliyetçi standartlar yüzünden romantik ilişkisinde de kendisini daha yetersiz ya da daha değersiz hissederek mutsuz olması ve hatta depresyona girmesi de oldukça olası görünmektedir. Bu durum da bireyin iyilik halini zedeleyecek bir faktör olarak karşımıza çıkabilir.

\section{Sinırlıklar}

Sosyal medya bağımlılığı, romantik ilişkilerde mükemmeliyetçilik ve iyilik hali arasındaki ilişkiler ağını ele alan bu çalışmada bazı sınırlıklar mevcuttur. Birinci sınırlık çalışmanın verilerinin toplandığı öz-bildirim (selfreport) ölçme araçlarından kaynaklanmaktadır. Dolayısıyla kavramlar ancak bu öz-bildirim ölçme araçlarının gücüyle sınırlıdır. Bununla birlikte öz-bildirim araçların doğası gereği sosyal istenirlik bulaşabileceği de göz önüne alınmalıdır. Sonraki çalışmalar partner değerlendirmesi, görüşme 
vb. farklı teknikleri de katabilecekleri düşünülmektedir. İkinci sınırlık verilerin genellenebilirliği ile ilgilidir. Çalışmanın verileri Doğu Karadeniz'de bir devlet üniversitenden elde edilmiştir. Sonraki çalışmalar Türkiye İstatistiki Bölge Birimleri Sınıflandırmasını (NUTS-II) kullanarak oranlı örnekleme ile katılımcıların dâhil edilmesini sağlayabilir. Son sınırlık da araştırmanın yönteminin kesitsel (cross-sectional) olmasından kaynaklanmaktadır. Çalışma her ne kadar nicel yöntemlerin güçlü tekniklerinden olan yapısal eşitlik modellemesi kullanılmış ve 10,000 yeniden örnekleme ile bootstrapping tekniği uygulanmış olsa da değişkenler arasındaki neden - sonuç bağını keskin bir şekilde ifade etmeyi sağlayamamaktadır. Sonraki çalışmalar boylamsal ya da deneysel bir yöntemle desenlenmeleri halinde değişkenlerin yönleri hakkında daha net sonuçlar ortaya koyabilecektir.

\section{Sonuç}

Sonuç olarak tüm bu sınırlıklarla birlikte bu çalışmada üniversite öğrencilerinde sosyal medya bağımlığının hem romantik ilişkilerinde ortaya çıkarabileceği problemlerin artmasında hem de kendi ruh sağlıklarına zarar verebilmesinde önemli bir rolünün olduğu ortaya konmuştur. Bununla birlikte romantik ilişkilerde mükemmeliyetçiliğin de iyilik halini zayıflatabilecek bir değişken olduğu belirlenmiştir. Ayrıca sosyal medya bağımlılığının iyilik hali üzerinde romantik ilişkilerde mükemmeliyetçiliğin aracllı̆̆ıyla da etkisinin olduğu saptanmıştır. Ortaya çıkan model göz önüne alındığında; psikolojik danışmanların bireylerin bağımlılıkları ile mücadele etmelerinde yardımcı olabilecek bireysel ve grupla psikolojik danışma uygulamaları yapmaları danışanların hem romantik ilişkilerine hem de iyi oluşlarına fayda sağlayacağa görülmektedir. 


\section{EXTENDED ABSTRACT}

\section{Social Media Addiction and Flourishing: The Mediating Role of Romantic Relationship Perfectionism \\ *

\author{
Begüm Satıc1 \\ Artvin Çoruh University
}

According to recent studies, $45 \%$ of the world population, in other words, approximately 3 billion 500 million people, use social media in an active manner. When Turkey is considered, it is seen that approximately 59 million 500 thousand people are active social media users, which is equivalent to $72 \%$ of the country population (Digital Report, 2019). When using social media in an uncontrolled way, it starts to prevent the fulfillment of other responsibilities in the life of an individual, it becomes possible to talk about social media addiction (Ryan et al., 2014).

It is observed that the use of social media is becoming a first priority for individuals by becoming more widespread and by affecting romantic relations in a negative way, and it is also a risk factor for both physical and spiritual health. It is considered that this might increase perfectionism both for the individual and for the partner, and it is estimated that it might affect the flourishing of individuals in a negative way. The state of flourishing, which indicates that life is going in a positive direction, is defined as a combination of feeling good and being functional. Also, it describes that a person is healthy and has mental health (Huppert \& So 2009; Ryff \& Singer, 2008).

Although the perfection of the experiences in virtual realm leaves a question mark in minds, it creates a new reality perception, and might lead to this unrealistic perfection in their lives after some time in individuals who use social networks frequently. For this reason, it was considered worth examining how this perfectionism, which can affect romantic relations of individuals, might affect the flourishing. Although there are studies in which the variables that are dealt with in the present study are examined separately, this study is considered to be important in terms of 
the absence of studies examining the variables together. For this reason, the purpose of the present study was to examine the mediating role of romantic relationship perfectionism between social media addiction and flourishing.

The participants of this study consisted of 354 university students who studied at Artvin Coruh University, Faculty of Education and Faculty of Letters. The ages of the participants ranged between 18 and 31 years; the average age was 20.80; and the standard deviation was 2.18. A total of 199 of the participants were female, and 155 were male; 96 of them were in the first grade, 91 in the second grade, 99 were in the third grade, and 68 were in the fourth grade.

The Flourishing Scale, the Social Media Disorder Scale, and the Romantic Relationship Perfectionism Scale were used as the data collection tools in the study. The data were obtained in face-to-face by the researcher in classrooms. Firstly, the descriptive statistics of the variables were examined; and the relations between the variables were dealt with. Then, the two-stage Structural Equation Modeling (SEM) was used in line with the suggestions of Anderson and Gerbing (1988). In this study, the Bootstrapping Technique was also employed to provide additional evidence for the significance of the paths of the best model that was obtained in SEM. A total of 10.000 bootstrapping was carried out to create the coefficients and the confidence intervals.

It was determined that flourishing negatively associated with social media addiction, self-oriented perfectionism, and partner-oriented perfectionism. On the other hand, there were positively significant relations among social media addiction, self-oriented perfectionism and partneroriented perfectionism.

In the measurement model, which is the first phase of the Structural Equation Modeling, four latent variables (flourishing, social media addiction, self-oriented perfectionism and partner-oriented perfectionism), and 8 observed variables, which made up these hidden variables, were included. As a result of the analysis, it was determined that the measurement model fit well.

Full mediator, partial mediator and two different alternative models were tested in the structural model. There were no direct paths from social media addiction to flourishing in the full mediator model. As a result of 
the analysis, it was determined that the SRMR (.09) and RMSEA (.10) coefficients were not within acceptable limits. The direct path leading to flourishing from social media addiction was added in the partial mediator model. When the Goodness-of-Fit indices of the partial mediator model were considered, it was determined that all of them were within acceptable limits. The Goodness-of-Fit indices of two alternative models were not found to be within acceptable limits. As a result, the partial mediator model was preferred. The bootstrapping technique was applied to the partial mediator model; and it was concluded that direct and indirect paths were significant.

In the present study, the mediating role of romantic relationship perfectionism between social media addiction and flourishing was examined. In this respect, four hypotheses were formed based on the review in the literature. In the first hypothesis of the study, it was determined that social media addiction predicted flourishing negatively. In the second hypothesis, it was determined that social media addiction predicted romantic relationship perfectionism positively. It was determined in the third hypothesis that romantic relationship perfectionism predicted flourishing in a negative way. The final hypothesis, which was supported by the findings of this study, is that romantic relationship perfectionism has a mediating role in relations between social media addiction and flourishing. It was also determined that the findings were consistent with the theoretical explanations, and were parallel to the results of previous studies.

In conclusion, in this study, with all its limitations, it was shown that social media addiction has an important role in increasing the problems that might arise in romantic relations and in damaging the mental health. However, it was also determined that perfectionism is a variable, which might weaken the flourishing.

\section{Kaynakça / References}

Akaike, H. (1987). Factor analysis and AIC. In Selected papers of hirotugu akaike (p. 371-386). Springer, New York, NY.

Anderson, J. C., ve Gerbing, D. W. (1988). Structural equation modeling in practice: A review and recommended two-step approach. Psychological Bulletin, 103(3), 411-423. 
Andreassen, C. S. (2015). Online social network site addiction: A comprehensive review. Current Addiction Reports, 2(2), 175-184.

Andreassen, C. S., Billieux, J., Griffiths, M. D., Kuss, D. J., Demetrovics, Z.,Mazzoni, E., ve Pallesen, S. (2016). The relationship between addictive use of social media and video games and symptoms of psychiatric disorders: A large-scale cross-sectional study. Psychology of Addictive Behaviors, 30(2), 252-262.

Andreassen, C. S., Pallesen, S., ve Griffiths, M. D. (2016). The relationship between excessive online social networking, narcissism, and self-esteem: Findings from a large national survey. Addictive Behaviors, 64, 287-293.

Arısoy, Ö. (2009). İnternet bağımlılığı ve tedavisi. Psikiyatride Güncel Yaklaşımlar, 1(1), 55-67.

Balcı, Ş., ve Baloğlu, E. (2018). Sosyal medya bağımlılı̆̆ı ile depresyon arasındaki ilişki: Üniversite gençliği üzerine bir saha araştırması. Galatasaray Üniversitesi Illetişim Dergisi, 29, 209-234.

Balcı, Ş., Gölcü, A., ve Gölcü, A. A. (2019). Sosyal medya kullanımı ile kendini gizleme ve yaşam doyumu arasında bir bağlantı var mı?. Afyon Kocatepe University Journal of Social Sciences, 21(1), 173-190.

Bardone-Cone, A. M., Wonderlich, S. A., Frost, R. O., Bulik, C. M., Mitchell, J. E., Uppala, S., ve Simonich, H. (2007). Perfectionism and eating disorders: Current status and future directions. Clinical Psychology Review, 27(3), 384-405.

Bergman, A. J., Nyland, J. E., ve Burns, L. R. (2007). Correlates with perfectionism and the utility of a dual process model. Personality and Individual Differences, 43(2), 389-399.

Blanchard, V. L., Hawkins, A. J., Baldwin, S. A., ve Fawcett, E. B. (2009). Investigating the effects of marriage and relationship education on couples' communication skills: A meta-analytic study. Journal of Family Psychology, 23(2), 203-214.

Browne, M. W., ve Cudeck, R. (1993). Alternative ways of assessing model fit. Sage Focus Editions, 154, 136-136.

Cabral, J. (2008). Is generation Y addicted to social media. Future of Children, 18, 5-14. 
Casale, S., Fioravanti, G., Flett, G. L., ve Hewitt, P. L. (2015). Self-presentation styles and Problematic use of Internet communicative services: The role of the concerns over behavioral displays of imperfection. Personality and Individual Differences, 76, 187-192.

Diener, E., Oishi, S., ve Lucas, R. E. (2003). Personality, culture, and subjective well-being: Emotional and cognitive evaluations of life. Annual Review of Psychology, 54(1), 403-425.

Diener, E., Wirtz, D., Tov, W., Kim-Prieto, C., Choi, D. W., Oishi, S., ve BiswasDiener, R. (2010). New well-being measures: Short scales to assess flourishing and positive and negative feelings. Social Indicators Research, 97(2), 143-156.

Digital Report (2019). Digital in 2019. https://wearesocial.com/global-digitalreport-2019 internet sitesinden 03.07.2019 tarihinde alınmıştır.

Duan, W., Ho, S. M., Tang, X., Li, T., ve Zhang, Y. (2014). Character strengthbased intervention to promote satisfaction with life in the Chinese university context. Journal of Happiness Studies, 15(6), 1347-1361.

Dunn, E., Aknin, L. B., ve Norton, M. I. (2008). Spending money on others promotes happiness. Science, 319, 1687-1688.

Ellis, A. (2002). The role of irrational beliefs in perfectionism. In (G. L. Flett, and P. L. Hewitt (Eds.), Perfectionism: Theory, research, and treatment (p. 217-229). Washington, DC: American Psychological Association.

Flett, G. L., ve Hewitt, P. L. (2002). Perfectionism and maladjustment: An overview of theoretical, definitional, and treatment issues. In (G. L. Flett \& P. L. Hewitt Eds.), Perfectionism: Theory, research, and treatment (p. 531). Washington, DC, US: American Psychological Association.

Flett, G. L., Hewitt, P. L., Shapiro, B., ve Rayman, J. (2001). Perfectionism, beliefs, and adjustment in dating relationships. Current Psychology, 20(4), 289-311.

Fowers, B. J., ve Owenz, M. B. (2010). A eudaimonic theory of marital quality. Journal of Family Theory \& Review, 2(4), 334-352.

Frangos, C. C. (2009). P01-31 Internet dependence in college students from Greece. European Psychiatry, 24, $\mathrm{S} 419$.

Frost, R. O., ve DiBartolo, P. M. (2002). Perfectionism, anxiety, and obsessivecompulsive disorder. In (G. L. Flett and P. L. Hewitt(Eds.), Perfectionism: Theory, research, and treatment (p. 341-371). Washington, DC, US: American Psychological Association. 
Griffiths, M. D. (2013). Social networking addiction: Emerging themes and issues. Journal of Addiction Research \& Therapy,4(5), e118. doi: 10.4172/2155-6105.1000

Habke, A. M., Hewitt, P. L., ve Flett, G. L. (1999). Perfectionism and sexual satisfaction in intimate relationships. Journal of Psychopathology and Behavioral Assessment, 21(4), 307-322.

Haferkamp, C. J. (1994). Dysfunctional beliefs, self-monitoring, and marital conflict. Current Psychology, 13(3), 248-262.

Haring, M., Hewitt, P. L., ve Flett, G. L. (2003). Perfectionism, coping, and quality of intimate relationships. Journal of Marriage and Family, 65(1), 143-158.

Hayes, A. F. (2018). Partial, conditional, and moderated moderated mediation: Quantification, inference, and interpretation. Communication Monographs, 85, 4-40.

Hewitt, P. L., ve Flett, G. L. (1991). Perfectionism in the self and social contexts: Conceptualization, assessment, and association with psychopathology. Journal of Personality and Social Psychology, 60, 456-470.

Hewitt, P. L., ve Flett, G. L. (1996). The multidimensional perfectionism scale. Toronto: Multi-Health Systems Inc.

Hewitt, P. L., Flett, G. L., ve Mikail, S. F. (1995). Perfectionism and relationship adjustment in pain patients and their spouses. Journal of Family Psychology, 9(3), 335-347.

Hone, L., Jarden, A., ve Schofield, G. (2014). Psychometric properties of the Flourishing Scale in a New Zealand sample. Social Indicators Research, 119(2), 1031-1045.

Huppert, F. A., ve So, T. (2009, July). What percentage of people in Europe are flourishing and what characterises them. In IX ISQOLS Conference (pp. 1-7).

Jelenchick, L. A., Eickhoff, J. C., ve Moreno, M. A. (2013). “Facebook depression?" Social networking site use and depression in older adolescents. Journal of Adolescent Health, 52(1), 128-130.

Joseph, D. (2019). The Rise of Social Media. http://activate-commerce.com/risesocial-media/ internet sitesinden 03.07.2019 tarihinde alınmıştır.

Karaca, M., ve Mutlu, T. (2019). Nispetizm-Miş gibi yapmak: Sosyal medyada nispet davranışları üzerine kavramsal bir çalışma. Anadolu Akademi Sosyal Bilimler Dergisi, 1(1), 40-51. 
Lenhart, A., Purcell, K., Smith, A., ve Zickuhr, K. (2010). Social Media \& Mobile Internet Use among Teens and Young Adults. Millennials. Pew internet $\&$ American life project.

Lin, J. H. (2016). Need for relatedness: A self-determination approach to examining attachment styles, Facebook use, and psychological well-being. Asian Journal of Communication, 26(2), 153-173.

Mackinnon, S. P., Kehayes, I. L. L., Leonard, K. E., Fraser, R., ve Stewart, S. H. (2017). Perfectionistic concerns, social negativity, and subjective wellbeing: A test of the social disconnection model. Journal of Personality, 85(3), 326-340.

Matte, M., ve Lafontaine, M. F. (2012). Assessment of romantic perfectionism: Psychometric properties of the romantic relationship perfectionism scale. Measurement and Evaluation in Counseling and Development, 45(2), 113-132.

Michalos, A. C. (1985). Multiple discrepancies theory (MDT). Social Indicators Research, 16(4), 347-413.

Monacis, L., De Palo, V., Griffiths, M. D., ve Sinatra, M. (2017). Social networking addiction, attachment style, and validation of the Italian version of the Bergen Social Media Addiction Scale. Journal of Behavioral Addictions, 6(2), 178-186.

Nasser-Abu Alhija, F., ve Wisenbaker, J. (2006). A Monte Carlo study investigating the impact of item parceling strategies on parameter estimates and their standard errors in CFA. Structural Equation Modeling, 13(2), 204-228.

Odacı, H., ve Çelik, Ç. B. (2013). Who are problematic internet users? An investigation of the correlations between problematic internet use and shyness, loneliness, narcissism, aggression and self-perception. Computers in Human Behavior, 29(6), 2382-2387.

Ozteke, H. I., Buyukbayraktar, C. G., ve Kesici, S. (2015). The adaptation of romantic relationship perfectionism scale into Turkish culture. The Anthropologist, 19(2), 387-395.

Pantic, I. (2014). Online social networking and mental health. Cyberpsychology, Behavior, and Social Networking, 17(10), 652-657.

Pantic, I., Damjanovic, A., Todorovic, J., Topalovic, D., Bojovic-Jovic, D., Ristic, S., ve Pantic, S. (2012). Association between online social networking and depression in high school students: behavioral physiology viewpoint. Psychiatria Danubina, 24(1.), 90-93. 
Rücker, J., Akre, C., Berchtold, A., ve Suris, J. C. (2015). Problematic Internet use is associated with substance use in young adolescents. Acta Paediatrica, 104(5), 504-507.

Ryan, R. M., ve Deci, E. L. (2000). Self-determination theory and the facilitation of intrinsic motivation, social development, and well-being. American Psychologist, 55(1), 68-78.

Ryan, T., Chester, A., Reece, J., ve Xenos, S. (2014). The uses and abuses of Facebook: A review of Facebook addiction. Journal of Behavioral Addictions, 3(3), 133-148.

Ryff, C. D. (1989). Happiness is everything, or is it? Explorations on the meaning of psychological well-being. Journal of Personality and Social Psychology, 57(6), 1069-1081.

Ryff, C. D., ve Singer, B. H. (2008). Know thyself and become what you are: A eudaimonic approach to psychological well-being. Journal of Happiness Studies, 9(1), 13-39.

Savci, M., Ercengiz, M., ve Aysan, F. (2018). Turkish adaptation of the Social Media Disorder Scale in adolescents. Archives of Neuropsychiatry, 55(3), 248-255.

Seabrook, E. M., Kern, M. L., ve Rickard, N. S. (2016). Social networking sites, depression, and anxiety: a systematic review. JMIR Mental Health, 3(4), e50.

Senol-Durak, E., ve Durak, M. (2011). The mediator roles of life satisfaction and self-esteem between the affective components of psychological well-being and the cognitive symptoms of problematic Internet use. Social Indicators Research, 103(1), 23-32.

Sirois, F. M., ve Molnar, D. S. (2016). Conceptualizations of perfectionism, health, and well-being: An introductory overview. In Perfectionism, health, and well-being (pp. 1-21). Springer, Cham.

Steers, M. L. N., Wickham, R. E., ve Acitelli, L. K. (2014). Seeing everyone else's highlight reels: How Facebook usage is linked to depressive symptoms. Journal of Social and Clinical Psychology, 33(8), 701-731.

Stoeber, J. (2012). Dyadic perfectionism in romantic relationships: Predicting relationship satisfaction and longterm commitment. Personality and Individual Differences, 53(3), 300-305.

Stoeber, J., ve Stoeber, F. S. (2009). Domains of perfectionism: Prevalence and relationships with perfectionism, gender, age, and satisfaction with life. Personality and Individual Differences, 46(4), 530-535. 
Tang, C., Guo, L., ve Gopinath, M. (2016). A social-cognitive model of consumer well-being: A longitudinal exploration of the role of the service organization. Journal of Service Research, 19(3), 307-321.

Telef, B. B. (2013). Psikolojik iyi oluş ölçeği: Türkçeye uyarlama, geçerlik ve güvenirlik çalışması. Hacettepe Üniversitesi Eğitim Fakültesi Dergisi, 28(23), 374-384.

van den Eijnden, R. J., Lemmens, J. S., ve Valkenburg, P. M. (2016). The social media disorder scale. Computers in Human Behavior, 61, 478-487.

Wu, A. M. S., Cheung, V. I., Ku, L., ve Hung, E. P. W. (2013). Psychological risk factors of addiction to social networking sites among Chinese smartphone users. Journal of Behavioral Addictions, 2(3), 160-166.

Yıldız, H (2017). Sosyal Medya Çağında Nispetizm Fenomeni. Harvard Business Review

Young, K., Pistner, M., O'mara, J., ve Buchanan, J. (1999). Cyber disorders: The mental health concern for the new millennium. CyberPsychology $\mathcal{E} B e-$ havior, 2(5), 475-479.

\section{Kaynakça Bilgisi / Citation Information}

Satıcı, B. (2019). Sosyal medya bağımlılığı ve iyilik hali: Romantik ilişkilerde mükemmeliyetçiliğin aracılık rolü. OPUS-Uluslararası Toplum Araştırmaları Dergisi, 14(20), 699-727. DOI: 10.26466/ opus.597950 